Otterbein University

Digital Commons @ Otterbein

Health and Sport Sciences Faculty Scholarship

Health and Sport Sciences

6-2006

\title{
Evaluating Transformational Leadership Skills of Hospice Executives
}

Paul D. Longenecker

Otterbein University

Follow this and additional works at: https://digitalcommons.otterbein.edu/hsports_fac

Part of the Health and Medical Administration Commons

\section{Repository Citation}

Longenecker, Paul D., "Evaluating Transformational Leadership Skills of Hospice Executives" (2006).

Health and Sport Sciences Faculty Scholarship. 6.

https://digitalcommons.otterbein.edu/hsports_fac/6

This Article is brought to you for free and open access by the Health and Sport Sciences at Digital Commons @ Otterbein. It has been accepted for inclusion in Health and Sport Sciences Faculty Scholarship by an authorized administrator of Digital Commons @ Otterbein. For more information, please contact

digitalcommons07@otterbein.edu. 


\title{
Evaluating Transformational Leadership Skills of Hospice Executives
}

American Journal of Hospice

\& Palliative Medicine

Volume 23 Number 3

June/July 2006 205-211

(C) 2006 Sage Publications

$10.1177 / 1049909106289082$

http://ajhpm.sagepub.com

hosted at

http://online.sagepub.com

\author{
Paul D. Longenecker, RN, MBA, PhD, CNAA, BC
}

Health care is a rapidly changing environment requiring a high level of leadership skills by executive level personnel. The hospice industry is experiencing the same rapid changes; however, the changes have been experienced over the brief span of 25 years. Highly skilled hospice executives are a necessity for the growth and long-term survival of hospice care. This descriptive study was conducted to evaluate the leadership skills of hospice executives. The study population consisted of hospice executives who were members of the state hospice organization in Ohio and/or licensed by the state ( 88 hospice providers). Three questionnaires were utilized for collecting data. These questionnaires collected data on

$\mathrm{T}$ The ever-changing world of the health care industry has required the emergence of the need for strong leaders with exceptional leadership skills. The role of leadership has been changing in most work environments, but few have changed as rapidly and as often as in the health care industry. ${ }^{1,2}$ Magnifying the impact of the change, the hospice industry has witnessed these changes over the brief span of 25 years. The changes affecting the hospice industry include changes within health care, in overall management practices, in employee expectations, and within society in general. To quantify the growth of hospice care, the number of people admitted to hospice care annually has grown from 1000 in 1975 to 700000 in $2000 .^{3}$

The hospice leader of today and into the future needs to be able to motivate not only themselves but also others, recognize impending changes and develop a plan to adapt to it, be able to work with people to

From The Transformational Group, LLC, and the School of Graduate and Professional Studies, Lourdes College, Sylvania, Ohio.

Address correspondence to: Paul D. Longenecker, RN, MBA, PhD, CNAA, BC, The Transformational Group, LLC, 558 Chestnut Avenue, Westerville, OH 43082; e-mail: plongenecker@ thetransformationalgroup.com. transformational leadership skills of participants, participants' personal demographics, and their employer's organizational demographics. Forty-seven hospice executives responded (53\%). Key findings reported were high levels of transformational leadership skills (mean, 3.39), increased use of laissez-faire skills with years of hospice experience $(P=.57)$, and positive reward being a frequent leadership technique utilized (mean, 3.29). In addition, this was the first study of leadership skills of hospice executives and the first formal collection of personal demographic data about hospice executives.

Keywords: hospice; leadership; transformational

match personnel skills with required duties, and be excited about what they do and convey it to others. ${ }^{4}$

The need for strong leadership skills in hospice executives is paramount to address the continuously changing world of palliative and end-of-life care. This study was undertaken to define a baseline of data regarding leadership skills of hospice executives. Transformational leadership theory was selected as the standard by which leadership skills were measured.

Transformational leadership theory is based on the need for leaders to be able to do more than manage the day-to-day transactions of working with others. Leaders need to be able to grow and enhance their followers, their organization, and themselves. This is achieved through the use of a higher level of skills.

\section{Transformational Leadership Theory}

Transformational leadership was first defined by James MacGregor Burns in 1978 and was formalized into a theory including models and measurement tools by Bernard Bass and Bruce Avolio in 1985..$^{5}$ Bass and Avolio reported that "close to 200 theses and dissertations on the subject" ${ }^{\prime(\mathrm{pl})}$ were written in the 4 years prior to 2000. The transformational model of leadership is 
divided into 3 main components: transformational leadership, transactional leadership, and laissez faire. These 3 components represent distinctive styles, beliefs, and behaviors utilized in leading others.

Transformational leadership is exhibited by 4 techniques: idealized influence (attributed and behavioral), inspirational motivation, individualized consideration, and intellectual stimulation. Idealized influence is displayed by the leader by serving as a role model. Leaders perform their job in a positive manner, and others aspire to emulate their behavior. Inspirational motivation is the ability to motivate and inspire others. The goal is to create an environment of team spirit with a common vision. Individualized consideration occurs when leaders strive to understand the individual needs of each of their followers and make them feel unique. Intellectual stimulation is achieved by facilitating their followers to look at things in new ways. Creativity is encouraged.

Transactional leadership focuses on exchanges between leaders and their subordinates. The 2 techniques used are contingent reward and managementby-exception (active and passive). Contingent reward is a system of positive rewards provided for the completion of a defined task. For example, if the subordinate completes a defined task (working an extra shift), he is rewarded in an agreed-upon way (an extra day off). If the task is not completed, no reward is provided. Positive reinforcement is the motivator utilized. In contrast, management-by-exception is based on negative reinforcement for subordinate errors that are found by the leader. Errors can be discovered by actively looking for them or by finding them by accident. The sole purpose is to provide punitive direction. No formal exchange occurs. The last area is laissez faire, which is defined as an absence of leadership. No formal or planned effort is provided to modify subordinate behavior. ${ }^{6}$

\section{Methods}

The study utilized a descriptive survey approach using questionnaires to collect data to address the research question, "Will all hospice executives demonstrate similar levels of Transformational Leadership Skills as measured by the Multifactor Leadership Questionnaire." The research sample was a purposive sampling based on the fact that the hospices in Ohio closely reflected the demographic characteristics of hospices in the United States. A comparison is outlined in Table 1.
Table 1. Comparison of NHPCO and OHPCO Data

\begin{tabular}{lcc}
\hline Category & NHPCO & OHPCO \\
\hline Type of program, \% & & \\
$\quad$ Freestanding & 36 & 55.9 \\
Hospital based & 36 & 26.5 \\
Home health & 1 & 14.7 \\
$\quad$ Nursing home & 20 & 5.9 \\
Profit status, \% & & \\
Not-for-profit & 87 & 91.7 \\
For profit & 13 & 8.3 \\
Medicare certified & 73 & 81.1 \\
Payer mix, \% of total days & & \\
Medicare & 80.2 & 44.6 \\
Medicaid & 5.1 & 9.0 \\
Private insurance & 12.2 & 1.8 \\
Self-pay & 0.8 & 0.6 \\
Other & 1.6 & 89.3 \\
ADC & 64.2 & 38 \\
Deaths (mean) & 389 & 4.7 \\
\% Died <7 days & 37 & 17 \\
\% Died 180+ days & 6.0 & \\
ALOS, d & 47.5 & \\
MLOS, d & 20.4 &
\end{tabular}

SOURCE: Ohio Summary Report: The 2001 NHPCO National Data Set. Columbus, Ohio: Ohio Hospice \& Palliative Care Organization and Perforum; 2003.

NOTE: NHPCO, National Hospice and Palliative Care Organization; OHPCO, Ohio Hospice and Palliative Care Organization; ADC, average daily census; ALOS, average length of stay; MLOS, median length of stay.

\section{Tools/Survey Process}

Three data collection tools were utilized to gather the research data. The Multifactor Leadership Questionnaire (MLQ) 5X Leadership Form, a tool developed by Bass and Avolio to rate leadership styles specific to the components of transformational leadership theory, was utilized. The MLQ consists of 45 questions utilizing a Likert scale. ${ }^{5}$ The second collection tool was a personal demographic questionnaire that gathered information about the participant's job title, area of specialization, level of education, years of leadership and hospice experience, age, and gender. The third collection tool was an organizational demographic questionnaire that gathered data on the participant's organization, including agency type, profit status, service area, annual budget, average daily census, and average and median length of stay of patients.

The 3 questionnaires, along with a cover letter explaining the purpose of the study, were mailed to all hospice executives of organizations that were members of the Ohio Hospice and Palliative Care Organization (OHPCO) and/or licensed by the State 
of Ohio. A self-addressed return envelope was sent with all surveys. Envelopes were numbered to verify questionnaires returned. Returned envelopes were unable to be linked to individual participants. Return of the questionnaires was used as consent for participation in study. Completion of the questionnaire took approximately 15 minutes.

For the purpose of this study, a hospice executive was defined as the individual holding the top leadership role within an organization. Only 1 survey was sent to each organization based on the OHPCO member list and/or State of Ohio licensure. A total of 88 surveys were mailed out.

\section{Statistical Methods}

Upon receiving completed questionnaires, responses were entered into a database utilizing Excel software, including the Analysis Toolpak. Descriptive statistics (means, percentages) were used for personal and organizational demographic data and responses on the MLQ. Pearson $r$ analysis was utilized to examine relationship between transformational leadership variables and personal and organizational demographic characteristics of participants. Analysis of variance (ANOVA) testing was utilized to evaluate relationships within groupings. An $\alpha$ level at the .05 level $(P<.05)$ of significance was utilized for all statistical analysis.

\section{Results}

A total of 47 hospice executives participated in the study. Of the 47 participants, only 30 participants returned all 3 questionnaires $100 \%$ completed, which included all personal and organizational demographic information and the 45 items on the MLQ. For purposes of analysis, only the questionnaires that were $100 \%$ completed were used. The 30 participants represent approximately $1 \%$ of all hospice executives in the United States.

The demographic information on the participants and their organizations are described in Table 2 . The most common characteristics of the hospice executives were as follows:

Job title: executive director $(56.7 \%)$

Area of specialization: nursing $(66.7 \%)$

Level of education: master's degree (43.3\%)

Years of leadership experience: 21 to 25 years (33.3\%)

Years of hospice experience: 16 to 20 years $(30 \%)$

Age: 51 to 60 years $(40 \%)$

Gender: female $(86.7 \%)$
Table 2. Personal Demographics and Organizational Characteristics

\begin{tabular}{|c|c|c|}
\hline Personal Demographics & $\mathrm{n}$ & $\%$ \\
\hline \multicolumn{3}{|l|}{ Job title } \\
\hline Executive director & 17 & 56.7 \\
\hline Other & 4 & 13.3 \\
\hline Administrator & 4 & 13.3 \\
\hline President/CEO & 4 & 13.3 \\
\hline Branch manager & 1 & 3.3 \\
\hline \multicolumn{3}{|l|}{ Area of specialization } \\
\hline Nursing & 20 & 66.7 \\
\hline Business & 6 & 20.0 \\
\hline Social work & 3 & 10.0 \\
\hline Medicine & 1 & 3.3 \\
\hline \multicolumn{3}{|l|}{ Level of education } \\
\hline Master's degree & 13 & 43.3 \\
\hline Bachelor's degree & 11 & 36.7 \\
\hline Associate degree & 3 & 10.0 \\
\hline Doctorate & 1 & 3.3 \\
\hline Nursing diploma & 1 & 3.3 \\
\hline High school & 1 & 3.3 \\
\hline \multicolumn{3}{|l|}{ Leadership experience, y } \\
\hline 21 to 25 & 10 & 33.3 \\
\hline 6 to 10 & 5 & 16.7 \\
\hline 11 to 15 & 5 & 16.7 \\
\hline 16 to 20 & 4 & 13.3 \\
\hline$<5$ & 4 & 13.3 \\
\hline$>25$ & 2 & 6.7 \\
\hline \multicolumn{3}{|l|}{ Hospice experience, y } \\
\hline 16 to 20 & 9 & 30.0 \\
\hline$<5$ & 7 & 23.3 \\
\hline 11 to 15 & 7 & 23.3 \\
\hline 6 to 10 & 5 & 16.7 \\
\hline 21 to 25 & 2 & 6.7 \\
\hline \multicolumn{3}{|l|}{ Age, y } \\
\hline 51 to 60 & 12 & 40.0 \\
\hline 41 to 50 & 10 & 33.3 \\
\hline$>60$ & 5 & 16.7 \\
\hline 31 to 40 & 2 & 6.7 \\
\hline$<30$ & 1 & 2.3 \\
\hline \multicolumn{3}{|l|}{ Gender } \\
\hline Female & 26 & 86.7 \\
\hline Male & 4 & 13.3 \\
\hline Organizational Characteristics & $\mathrm{n}$ & $\%$ \\
\hline \multicolumn{3}{|l|}{ Agency type } \\
\hline Freestanding & 16 & 53.3 \\
\hline Hospital based & 8 & 21.7 \\
\hline Home health & 3 & 10.0 \\
\hline Other & 2 & 6.7 \\
\hline Nursing home-based & 1 & 3.3 \\
\hline \multicolumn{3}{|l|}{ Profit status } \\
\hline Not-for-profit & 28 & 93.3 \\
\hline For profit & 2 & 6.7 \\
\hline \multicolumn{3}{|l|}{ Service area } \\
\hline Both rural and urban & 15 & 50.0 \\
\hline Rural & 13 & 43.3 \\
\hline Urban & 2 & 6.7 \\
\hline
\end{tabular}

(continued) 
Table 2 (continued)

\begin{tabular}{lrr}
\hline Organizational Characteristics & $\mathrm{n}$ & $\%$ \\
\hline Annual budget & & \\
$>\$ 5$ million & 10 & 33.3 \\
$>\$ 1$ million to $\$ 2$ million & 6 & 20.0 \\
$>\$ 2$ million to $\$ 3$ million & 5 & 16.6 \\
$>\$ .5$ million to $\$ 1$ million & 3 & 10.0 \\
$<\$ .5$ million & 3 & 10.0 \\
$>\$ 3$ million to $\$ 5$ million & 3 & 10.0 \\
ADC & & \\
51 to 100 patients & 8 & 26.7 \\
$<25$ patients & 7 & 23.3 \\
101 to 250 patients & 7 & 23.3 \\
26 to 50 patients & 6 & 3.3 \\
251 to 500 patients & 1 & 3.3 \\
$>500$ patients & 1 & \\
\hline
\end{tabular}

NOTE: ADC, average daily census

Table 3. Self-Scores of Hospice Executives

\begin{tabular}{lll}
\hline Factor & Mean & SD \\
\hline Transformational & 3.39 & 0.66 \\
$\quad$ Idealized influence (attributed) & 3.225 & 0.395 \\
Idealized influence (behavioral) & 3.52 & 0.40 \\
Intellectual stimulation & 3.31 & 0.42 \\
Individualized consideration & 3.42 & 0.46 \\
Inspirational motivation & 3.49 & 0.40 \\
Transactional & 2.06 & 0.36 \\
Contingent reward & 3.29 & 0.49 \\
Management-by-exception (active) & 1.59 & 0.70 \\
Management-by-exception (passive) & 1.31 & 0.60 \\
Laissez faire & 0.66 & 0.53 \\
\hline
\end{tabular}

The mean age of participants was 51.1 years with an SD of 8.58 years, average years of leadership experience was 16.2 with an SD of 8.17, and average years of hospice experience was 12.1 with an SD of 6.38 .

The most common characteristics of participants' organizations were as follows. Agency type: freestanding (53.3\%); profit status: not-for-profit $(93.3 \%)$; service area: both rural and urban (50\%); annual budget: greater than $\$ 5$ million $(33.3 \%)$; average daily census: 51 to 100 patients $(26.7 \%)$.

The self-scores of the participants on the MLQ for the 3 main components of transformational leadership theory were transformational leadership (3.39), transactional leadership (2.06), and laissez faire (0.66). Breakdown of main components and subcomponents are reflected in Table 3. All 5 subcomponents of transformational leadership had higher mean scores than did the 3 transactional leadership subcomponents except idealized influenceattributed (3.225).

In assessing the correlation between the 3 leadership styles and the 8 individual leadership techniques and the personal and organizational characteristics, limited statistically significant relationships were found. All Pearson $r$ results can be found in Table 4.

Years of hospice experience had statistically significant findings in 3 areas. Years of hospice experience had a moderate, positive correlation with laissez faire $(P=.57)$, a weak, negative correlation with individualized consideration $(P=-.37)$, and a moderate, positive correlation with management-byexception (passive) $(P=.47)$.

Average daily census (ADC) and median length of stay (MLOS) each had statistically significant findings in 2 areas. ADC had a very strong, negative correlation with transactional leadership $(P=-0.86)$ and weak, positive correlation with intellectual stimulation $(P=.38)$. MLOS had a moderate, negative correlation with idealized influence-attributed $(P=-.55)$ and a weak, positive correlation with individualized consideration $(P=.35)$

No statistically significant findings were noted in the evaluation of variances between and among the personal and organizational characteristics using ANOVA.

\section{Discussion}

The research findings demonstrated that the hospice executives surveyed reported the utilization of a high level of transformational leadership skills. These findings were similar to the Ohman study ${ }^{7}$ and results reported by Bass and Avolio in the development and testing of the MLQ. ${ }^{5}$

An area of interest from the study was the lack of comparative data on personal characteristics of hospice executives. Although data have been collected informally and anecdotally, no formal collection of descriptive information about hospice executives exists. This study was the first formal collection of this information. In developing training programs, this absence of information creates a void in being able to tailor training to the unique characteristics of the population. 
Table 4. Pearson Product-Moment Correlation Coefficients of Leadership Styles

\begin{tabular}{lccc}
\hline & \multicolumn{2}{c}{ Leadership Style } \\
\cline { 2 - 4 } Characteristic & Transformational & Transactional & Laissez Faire \\
\hline Level of education & -0.003 & 0.03 & 0.12 \\
Years of leadership experience & 0.1 & 0.32 & 0.33 \\
Years of hospice experience & -0.04 & 0.29 & 0.57 \\
Age & 0.09 & 0.2 & 0.14 \\
Annual budget & 0.21 & 0.02 & 0.07 \\
ADC & 0.15 & 0.001 & 0.09 \\
ALOS & 0.23 & -0.86 & -0.1 \\
MLOS & 0.27 & -0.1 & -0.32 \\
\hline
\end{tabular}

\begin{tabular}{lccccccrr}
\hline & \multicolumn{7}{c}{ Leadership Technique } \\
\cline { 2 - 9 } Characteristic & \multicolumn{1}{c}{ II-A } & \multicolumn{1}{c}{ II-B } & IS & \multicolumn{1}{c}{ IC } & IM & \multicolumn{1}{c}{ CR } & MBE-A & MBE-P \\
\hline Level of education & -0.15 & 0.06 & 0.02 & -0.08 & 0.16 & -0.01 & 0.19 & -0.16 \\
Years of leadership experience & 0.16 & -0.16 & 0.24 & 0.02 & 0.09 & -0.09 & 0.29 & 0.17 \\
Years of hospice experience & 0.22 & -0.06 & 0.16 & -0.37 & -0.03 & -0.25 & 0.21 & 0.47 \\
Age & 0.18 & -0.08 & 0.06 & -0.06 & 0.17 & 0.3 & -0.14 & 0.28 \\
Annual budget & 0.1 & 0.11 & 0.15 & -0.3 & 0.09 & -0.04 & 0.08 & 0.07 \\
ADC & -0.04 & 0.18 & 0.38 & -0.4 & 0.3 & 0.07 & 0.04 & -0.1 \\
ALOS & 0.08 & 0.28 & 0.14 & 0.07 & 0.26 & 0.04 & -0.17 & 0.01 \\
MLOS & -0.55 & 0.15 & 0.07 & 0.35 & 0.07 & 0.07 & -0.03 & -0.19 \\
\hline
\end{tabular}

NOTE: $P=.349$ for all Pearson $r$ analyses. Pearson $r$ results that are bold were statistically significant. II-A, idealized influence-attributed; II-B, idealized influence-behavioral; IS, intellectual stimulation; IC, individualized consideration; IM, inspirational motivation; CR, contingent reward; MBE-A, management-by-exception (active); MBE-P, management-by-exception (passive); ADC, average daily census; ALOS, average length of stay; MLOS, median length of stay.

In the analysis of the data, several patterns were noted:

1. Contingent reward had a higher mean score than did idealized influence-attributed for the majority of the groupings. The significance of this finding is that the hospice executives' perception of their followers was that they were more likely to be motivated by positive rewards for their performance than respected and admired for their leadership ability. Although both leadership techniques are based on positive leadership skills, idealized influence-attributed is based on the level of confidence that the leader has that one can influence followers by indirect means.

2. The differential between the highest and lowest mean scores for all personal characteristics and the majority of organizational characteristics was the narrowest between the transformational leadership scores for all 3 leadership styles. This appears to reflect that the research study participants had more similarities in their use of transformational leadership skills then they had in their utilization of the other 2 leadership styles. In addition, the differential between transactional leadership techniques was narrower than laissez faire.
3. The research study's organizational demographic data closely mirrored comparative data for hospices in the state of Ohio. The sample used for the study represented approximately $34.5 \%$ of all hospices in Ohio. The high percentage of representation of hospices in Ohio increases the ability to compare the research findings to all hospices in Ohio.

While the response rate of $53 \%$ was acceptable, the useable portion of the surveys was limited to $36 \%$ of the survey population. Several reasons for this outcome were thought to exist: (1) the hospice executives involved had limited access to organizational information (10 surveys were missing organizational data), and (2) there was a reluctance to share information with the researcher, who was involved in the hospice industry in Ohio.

\section{Personal Characteristics}

In evaluating the personal characteristics of the participants, a key area of interest were the findings related to the weak to moderate correlations that 
were found in 3 areas that involved years of hospice experience (YHE). The first area demonstrated that as YHE increased, utilization of laissez-faire leadership or no leadership increased. A second area was as YHE increased, the utilization of individualized consideration decreased, and in the third area as YHE increased, the utilization of management-by-exception (passive) increased.

All 3 tendencies identified appear to demonstrate lower level of utilization of strong transformational leadership skills as YHE increased. These correlations may demonstrate a change in leadership practices as hospice executives obtain more hospice experience. This finding could demonstrate several possible behavior patterns by the hospice leaders: (1) an increased comfort with the utilization of nontransaction by letting certain situations resolve without intervention, (2) a lack of willingness to get involved in resolving issues, or (3) the possibility of "burnout" or fatigue related to the length of time being involved in hospice care.

However, these findings pertained only to YHE and not years of leadership experience. No statistically significant findings were found with years of leadership experience or any of the other different leadership variables. This would appear to identify a potential difference in leadership skills of individuals who were attracted to hospice in its early stages versus those whose have involved in hospice care more recently.

Without further research and analysis, it is not possible to substantiate or validate the findings or provide a viable explanation for these results.

\section{Organizational Characteristics}

Organizationally, several patterns were noted. A very strong, negative relationship was found between average length of stay (ALOS) and transactional leadership, whereby as ALOS increased the utilization of transactional leadership skills decreased. While this finding is statistically significant, its applicability is limited without corresponding statistically significant relationships being found between ALOS and transformational leadership and laissez faire or both. Both of the other leadership styles had weak to no relationship noted during statistical analysis. The relationship between ALOS and transactional leadership could demonstrate a positive utilization of transformational leadership theory, if the utilization of transformational leadership had a positive relationship with ALOS and laissez faire had a negative relationship with ALOS. Without statistically significant support of those relationships, no implications can be stated.

A second pattern noted involved the weak, positive relationship that exists between average daily census (ADC) and intellectual stimulation, representing an increase in the use of intellectual stimulation when the ADC of an organization increased. This finding may indicate that when hospice patients receive care for longer periods of time, the hospice executives has more time to be involved in challenging the creative skills of their subordinates in caring for their patients. In addition, the increased ADC may allow the hospice executives the time to work on increasing the awareness of their staff on other issues or areas of practice.

\section{Limitations}

The limitations of the study were (1) the low number of survey questionnaires that were returned totally completed for all demographic and leadership areas and (2) the wide variance in the number of individuals in the individual groupings within certain personal and organizational characteristics. These limitations placed restraints on the ability to generalize the results to the total population of hospice executives.

\section{Future Study}

Areas for future study involve the replication of this study on a larger scale. The study could be done on a regional or national basis to validate or dispute the results of this study. A second area of data collection would the completion of a national data collection on characteristics of hospice executives. A third area of study would be the completion of both Leader and Rater form of the MLQ to validate the perception of hospice executive leadership skills with those of their subordinates.

In the completion of future research, specific attention should be directed toward the impact of YHE on leadership skills. If the current study findings are replicated, a distinctive pattern will have been identified that will affect the training plans for hospice executives. In addition, the data collection process needs to be enhanced to increase the thoroughness of the surveys returned. 


\section{Conclusion}

Overall, the findings of the study on evaluating the transformational leadership styles of hospice executives identified that the transformational leadership skills of hospice executives appear to represent that the hospice executives surveyed perceived that they utilized high levels of transformational leadership skills. In addition, the transactional leadership skills and laissez-faire skill results reflected the optimal pattern of utilization as suggested by Bass and Avolio. ${ }^{5}$

Based on the overall study findings, hospice executives would appear to be prepared to deal with the changing environment of health care and hospice. However, the findings related to YHE warrant future investigation to determine the validity of these results and use as a predictor of leadership skills of hospice executives.

In addition, with the study being the first research of leadership skills of hospice executives ever completed, the findings serve as a strong baseline on to which additional studies can be built. Because of the limited statistically significant findings and small sample size, the applicability of the findings is restricted without further study.

\section{References}

1. Heinman EA. Leadership profiles of senior nurse executives. Can J Nursing. 2000;13:21-30.

2. McConnell CR. The changing face of health care management. Health Care Manag (Frederick). 2000;18(3):1-17.

3. Miller G, Williams J, English D, et al. Delivering Quality Care and Cost-effectiveness at the End of Life [monograph]. Arlington, VA: National Hospice and Palliative Care Organization; 2002.

4. Porter-O'Grady T. Executive leadership: a new age demands new skills. Health Care Food Nutr Focus. 2001;18(4):5-7.

5. Bass B, Avolio B. MLQ: Multifactor Leadership Questionnaire. 2nd ed, Sample Set. Redwood City, Calif: Mindgarden, Inc; 2000.

6. Bass B, Avolio B. Introduction. In: Bass B, Avolio B, eds. Improving Organizational Effectiveness Through Transformational Leadership. Thousand Oaks, CA: Sage Publications; 1994:1-9.

7. Ohman KA. The transformational leadership of critical care nurse-managers. Dimens Crit Care Nurs. 2000;19:46-53. 